\title{
Thoracolumbar vertebral reconstruction after surgery for metastatic spinal tumors: long-term outcomes
}

\author{
Alan T. Villavicencio, M.D., Rod J. Oskouian, M.D., Cliff Roberson, M.D., \\ John Stokes, M.D., Jongsoo Park, M.D., Christopher I. Shaffrey, M.D., \\ and J. Patrick Johnson, M.D.
}

Department of Neurological Surgery, University of Virginia Health System, Charlottesville, Virginia; and Cedars-Sinai Institute for Spinal Disorders, Los Angeles, California

\begin{abstract}
Object. Metastatic spinal tumors continue to represent a major problem for patients and treating physicians. The purpose of this study was to assess quantitatively the functional outcome, quality of life, and survival rates of patients after major reconstructive spine surgery.

Methods. A prospective database was established and 58 patients were identified who had undergone thoracolumbar vertebral reconstruction for metastatic spinal tumors between March 1993 and October 1999. Surgical indications included disabling pain (92\%) and/or progressive neurological dysfunction (60\%).

Forty-nine patients $(85 \%)$ had clinical improvement in pain as determined based on the Oswestry pain scale $(\mathrm{p}<$ 0.05); $60 \%$ demonstrated improvement in their neurological status. The mean neurological improvement in Frankel grade was $1.2(\mathrm{p}<0.05)$. The 12 -month survival rate was $65 \%$, and all patients who were ambulatory after surgery remained so until the time of death. Instrumentation failure requiring repeated operation occurred in two patients $(3.5 \%)$, and in 12 patients $(21 \%)$ local tumor recurrence necessitated repeated surgery. There were no cases of neurological deficit or death related to surgery.

Conclusions. Major anterior thoracolumbar vertebral reconstruction is an effective treatment for local tumor control. More importantly, the authors have demonstrated that surgical treatment can significantly improve the quality of life by improvement of pain control and maintenance of ambulation during the patient's remaining life span.
\end{abstract}

\section{KEY WORDS • metastatic disease • vertebral column • reconstruction • outcome • quality of life}

Despite recent advancements in the medical management of metastatic disease in the spine, surgery continues to play a central role. ${ }^{28}$ Proper patient selection and appropriate surgical intervention continues to be a frequent cause for concern among spine surgeons. Ambulation at the time of death and long-term functional viability is a primary concern when considering reconstructive spinal surgery in cancer patients, because the vertebral column is the most common site of skeletal metastases. ${ }^{23,33}$ The older oncology literature reported that surgery combined with radiotherapy did not improve survival rates any more than radiotherapy alone. 5,20 The validity of these studies is unclear; they are very dated, poorly designed, and often reach inaccurate conclusions. More recent studies have demonstrated improved outcomes and lower morbidity after surgery. $7,8,15,25$, $26,50,56$ With increased survival times, spine surgeons are now more frequently faced with difficult decisions regarding treatment in patients with extensive lesions. Although palliative treatment is appropriate in some instances, resection

Abbreviations used in this paper: $\mathrm{CT}=$ computerized tomography; MR = magnetic resonance. can have potential beneficial effects on neurological func-

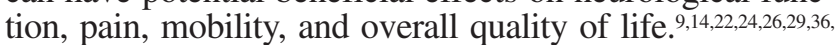
37,47,56 Moreover, tumor progression causing paraplegia may actually result in increased medical costs as well as decreased quality of life. ${ }^{21}$

Our goal with this paper was to provide outcome data in patients with metastatic thoracolumbar vertebral tumors requiring major surgery. In particular, we were interested in providing data regarding ambulatory status, neurological function, and patient longevity.

\section{CLINICAL MATERIAL AND METHODS}

\section{Patient Population}

Fifty-eight patients who had undergone thoracolumbar vertebral reconstruction for metastatic spinal tumors between March 1993 and October 1999 were identified (Table 1). Data were prospectively collected in a computerized database after a retrospective review of the medical records. All surgeries were performed by the senior author (J.P.J.). The mean age of the patients was 51 years (range 35-73 years). 
TABLE 1

Types of metastases in 58 patients

\begin{tabular}{lc}
\hline \hline Type of Metastasis & No. of Patients $(\%)$ \\
\hline renal & $19(33)$ \\
lung & $12(21)$ \\
plasmacytoma & $8(14)$ \\
breast & $6(10)$ \\
colon & $4(7)$ \\
bladder & $4(7)$ \\
thyroid & $2(3)$ \\
ovarian & $2(3)$ \\
leiomyosarcoma & $1(2)$ \\
total & $58(100)$ \\
\hline
\end{tabular}

\section{Patient Selection}

Patient selection criteria included the presence of at least one spinal metastasis with a previous diagnosis based on tissue analysis and a patient life expectancy greater than 6 months. The biological behavior of the tumor (that is, tissue of origin, tumor progression, bone predilection/tropism) was taken into consideration. Indications for surgery included metastatic vertebral instability, disease-related fracture, disabling pain, and progressive neurological deficit.

In all patients undergoing surgery for disabling pain, palliative treatment with bed rest, orthotic devices, nonsteroidal antiinflammatory drugs, and narcotic medications had failed. Each patient had also completed 4 to 8 weeks of physiotherapy and in some cases had received epidural injections. Primary symptoms at the time of surgery included pain in 53 patients $(92 \%)$ and progressive paraparesis in 35 $(60 \%)$.

A complete history, physical and neurological examination, and review of symptoms was performed in all pa- tients. Bowel and bladder status was documented. The general overall health of the patient and nutritional status were also assessed. Standard metastatic and laboratory workups as well as cancer staging included complete blood count and serum chemistry analysis that were collected before surgery. Plain radiography and CT myelography or MR imaging of the entire spine was performed in all patients. Preoperative arteriography and embolization was performed in select cases. Radiological evaluation for metastatic workup also included chest X-ray films, CT scanning, or MR imaging of the head, chest, abdomen, and pelvis, and mammography in women. Medical and radiation oncologists were involved at an early stage to establish that a multidisciplinary care approach was followed. All patients underwent preoperative radiation or chemotherapy where appropriate, unless they presented with acute neurological deterioration (one patient).

\section{Surgical Technique}

Selection of the surgical approach was based on anterior, middle, or posterior column involvement of the spine as well as the patient's overall medical condition. If the tumor was located posteriorly then a posterior approach was performed, with supplemental instrumentation if there was evidence of instability. A combined anteroposterior approach was considered for the following conditions: extensive circumferential tumor (three-column involvement); significant vertebral instability in which anterior stabilization alone was deemed insufficient to restore spinal stability; marked kyphosis; multilevel vertebral body involvement; prior laminectomy at the level of the tumor; and junctional (that is, the cervicothoracic or thoracolumbar junction) site of involvement (Figs. 1-4). In general, the side of the tumor mass was the one from which we made our approach; otherwise we used the left side (Table 2).
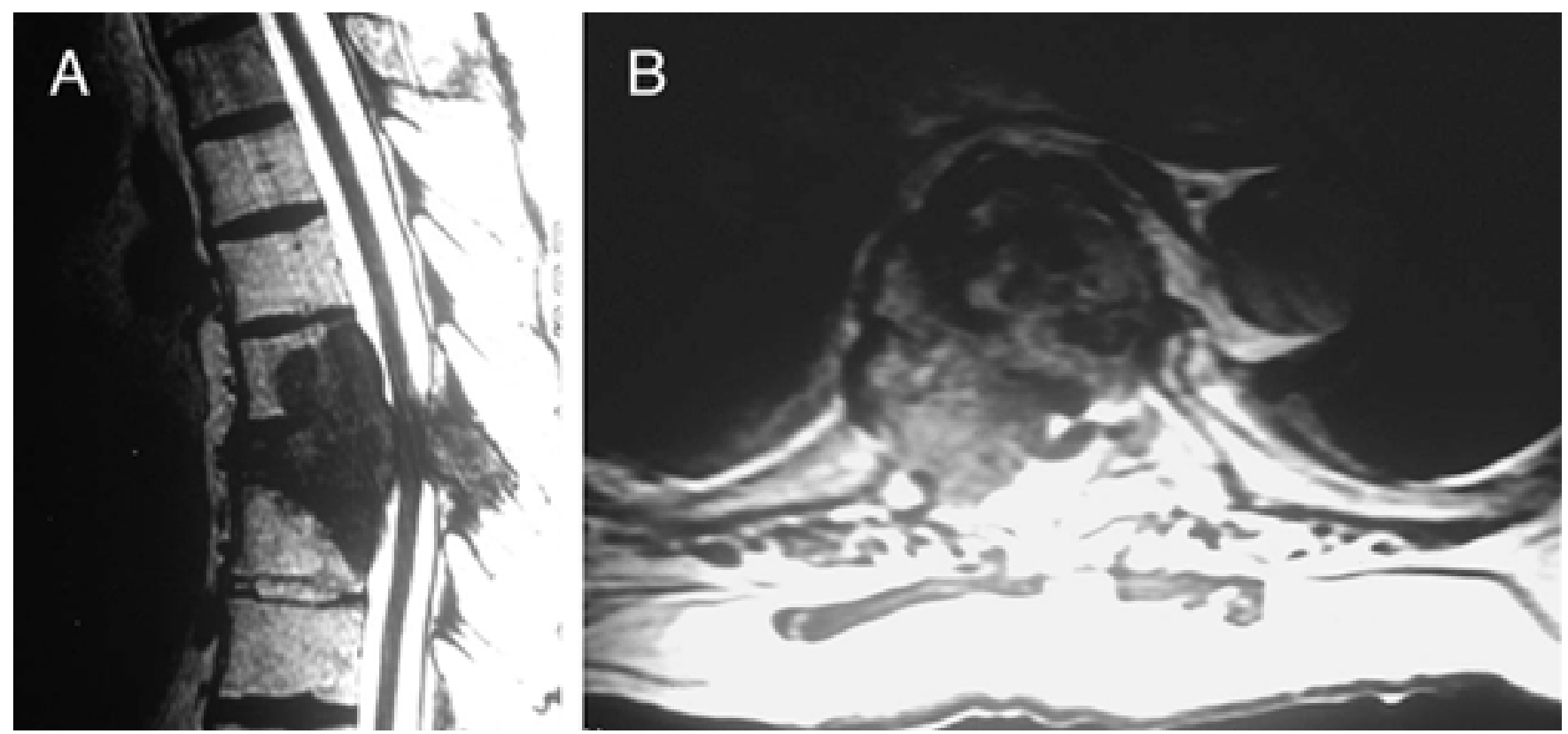

Fig. 1. Preoperative sagittal (A) and axial (B) MR images obtained in a 56-year-old patient with metastatic renal cell carcinoma and progressive paraparesis. 

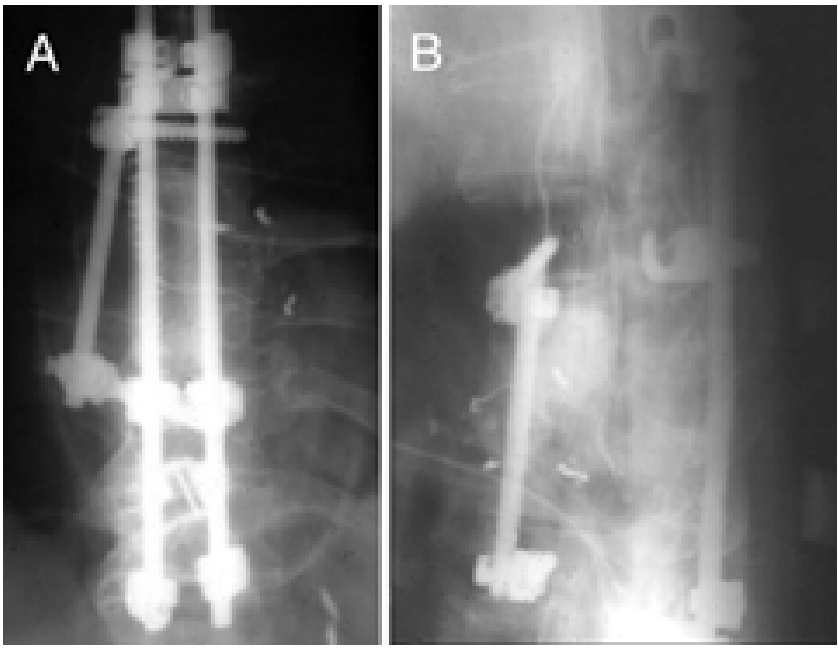

Fig. 2. Follow-up x-ray films of the thoracic spine (A, lateral view; $\mathrm{B}$, anteroposterior view) showing the spinal reconstruction 2 years later.

The vertebral body defect was reconstructed using either femoral shaft (allograft), an expandable cage, a titanium mesh cage, or a vertical titanium mesh cage filled with allograft bone. An anterior thoracolumbar locking instrumentation construct was placed to provide additional anterior spinal stabilization. A chest tube was placed in the thoracic cavity, followed by a standard closure. The chest tube was removed when the amount of drainage at 24 hours was less than $150 \mathrm{ml}$. Additional posterior segment instrumented fusion was performed if indicated.

\section{Clinical Follow-Up Evaluation}

After surgery, patients were examined daily while in the hospital and then at 1 and 6 weeks after discharge. Followup evaluations were then conducted at 3- to 6-month intervals for the 1st year and thereafter for the remainder of the patient's life. The level of pain present preoperatively was
TABLE 2

Surgical approaches in relation to tumor location

\begin{tabular}{cl}
\hline \hline Location & \multicolumn{1}{c}{ Approach } \\
\hline T1-2 & transcervical route \\
T2-3 & median sternotomy \\
T3-5 & high anterolat/retropectoral thoracotomy \\
T5-L3 & anterolat thoracotomy \\
\hline
\end{tabular}

assessed individually by the patient during the routine preoperative workup. Postoperatively, the level of pain present was again assessed individually by the patient during each clinic visit. If the patient was unavailable due to geographic limitations, the follow-up evaluation was performed by the family physician and the spine clinic nurse practitioner through routine phone interviews. The outcome measures at each evaluation included documenting measurements from a modified Frankel scale assessing neurological function, the Oswestry pain scale, ambulation status, and bowel and bladder function. Longevity and functional status (that is, ambulation and bowel/bladder function) were the major factors evaluated in this study.

\section{RESULTS}

Surgical approaches and location are summarized in Table 3, which shows that $36(62 \%)$ of 58 patients underwent anterior tumor resection and vertebral body reconstruction in the thoracic spine and $22(38 \%)$ underwent this procedure in the lumbar spine. Twenty-five (69\%) of 36 patients who underwent surgery in the thoracic spine had anterior procedures only, whereas $11(31 \%)$ had both anterior and posterior surgery. Fourteen (64\%) of 22 patients who underwent surgery on the lumbar spine had anterior procedures only, whereas eight (36\%) had both anterior and posterior surgery. The number of levels treated usually consisted of one or two vertebrae reconstructed, with a small number of three- and four-level procedures (Table 4). Forty-two (72\%) of 58 patients underwent vertebral body
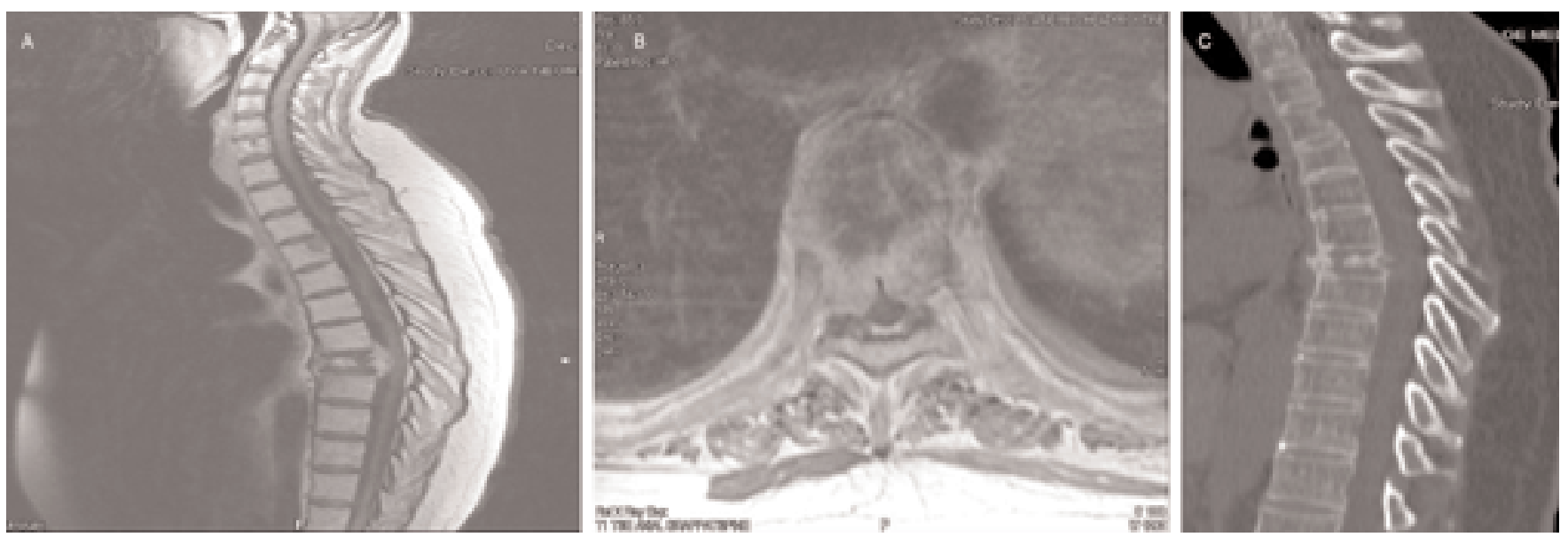

Fig. 3. Preoperative MR images of a T-7, disease-related fracture with spinal cord compression and progressive neurological deficit secondary to metastasis in a patient with known renal cell cancer. (A and C, sagittal views of cervical and thoracic spine; B, axial view of thoracic spine. 
A. T. Villavicencio, et al.
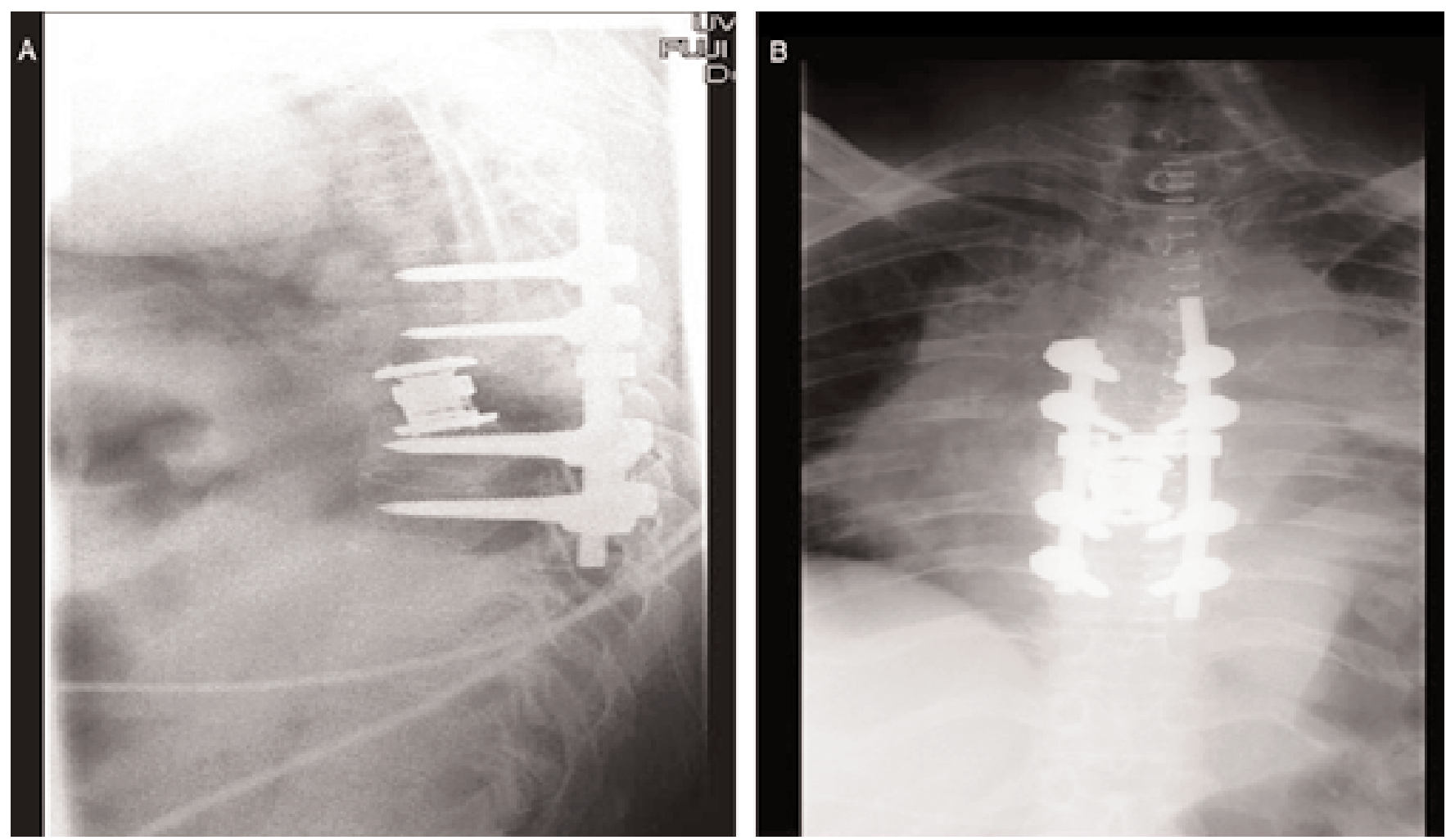

Fig. 4. Postoperative lateral (A) and anteroposterior (B) X-ray films obtained 15 months after the procedure in the patient with the T-7, disease-related fracture, who underwent T5-9 posterior segmental instrumentation and fusion. An anterolateral approach was used to perform the T-7 vertebrectomy and an expandable cage with local and allograft bone was inserted.

reconstruction anteriorly in which a Harms cage (DePuy AcroMed, Inc. [Johnson \& Johnson], Raynham, MA) was used; in 16 patients $(28 \%)$ femoral shaft allografts were inserted. All patients received additional stabilization anteriorly by using either a Z-plate (Medtronic Sofamor-Danek, Memphis, TN) or a Profile plate (DePuy AcroMed, Inc.) construct. Nineteen (33\%) of 58 patients underwent additional posterior instrumentation for further resection and stabilization.

Follow-up data were obtained in 44 of 58 patients, representing a $76 \%$ follow-up rate, and those in whom information was unavailable had died of their underlying metastatic disease and were not lost to follow up. In $49(85 \%)$ of the 58 patients, their pain had improved relative to their preoperative status, it was unchanged in nine (15\%), and no patient reported worsened pain. Sixteen (57\%) of the 28 patients with incomplete incontinence preoperatively had clinical improvement in bladder function after surgery. No patient with complete incontinence preoperatively had improvement in bladder function postoperatively.

The majority of our patients (34) were ambulatory preoperatively, and $32(94 \%)$ of this group remained ambulatory postoperatively, whereas only two (6\%) lost the ability to walk before they died of unrelated causes (Table 5). Of the 24 patients who were nonambulatory preoperatively, $15(62 \%)$ regained ambulatory function, whereas nine (38\%) remained nonambulatory but had some useful lower-extremity function allowing mobilization transfers. Fourteen (24\%) of 58 patients were alive at the time this pa- per was written. The mean duration of survival was 13 months (range 3-38 months).

\section{Surgical Complications}

Three patients experienced wound infections postoperatively that required reoperation for debridement. All hardware was left in place and the patients were treated thereafter with a 6-week course of antibiotic drugs. Four patients suffered pneumonia that was treated medically. Two patients experienced cerebrospinal fluid leaks that were managed with lumbar drains; neither of these required reoperation. In three patients, deep venous thromboses were diagnosed and were treated with anticoagulation therapy. More importantly, we had to repeat the operation in 12 patients $(21 \%)$ for local recurrence of the metastases. We also found that two patients in this group of 12 who had local recurrence experienced pseudarthrosis secondary to local recurrence and progression of disease.

\section{DISCUSSION}

\section{Background on Metastatic Spinal Tumors}

Metastases account for $70 \%$ of all vertebral column tumors. ${ }^{41}$ Although the lumbar spine is the most frequent site of spinal metastases overall, more than $70 \%$ of symptomatic metastases occur in the thoracic spine, whereas the cervical and lumbar regions are affected in 10 and $20 \%$ of cases, respectively. ${ }^{21,50}$ The most frequently arising solid 
Metastatic spinal tumors: vertebral reconstruction postsurgery

TABLE 3

Surgical approaches in 58 patients who underwent reconstructive thoracolumbar vertebrectomy for metastatic spinal tumors*

\begin{tabular}{llcl}
\hline \hline Location & Ant $(\%)$ & Ant \& Pst $(\%)$ & Total $(\%)$ \\
\hline thoracic & $25(69)$ & $11(31)$ & $36(62)$ \\
lumbar & $14(64)$ & $8(36)$ & $22(38)$ \\
total no. & $39(52)$ & $19(48)$ & $58(100)$ \\
\hline
\end{tabular}

$*$ Ant $=$ anterior; pst $=$ posterior.

metastatic spinal lesions are breast, lung, prostate, and renal cell carcinomas. ${ }^{6}$ Lung cancer is the most common neoplasm in males, whereas breast cancer is the most frequent one in females. ${ }^{25}$ Less frequently observed are thyroid and gastrointestinal carcinomas. ${ }^{50}$ Of the lymphoreticular malignancies, multiple myeloma and lymphoma are frequent causes of disseminated spinal lesions. ${ }^{10}$ In this series, we had a predominance of renal cell carcinoma $(31 \%)$, followed by lung cancer $(21 \%)$, plasmacytoma (14\%), and breast cancer $(10 \%)$ that were likely due to referrals to a specialty oncology center. There were no cases of metastatic prostate carcinoma.

\section{Outcomes for Pain Improvement}

Pain was the most common symptom (92\% of patients) associated with metastatic thoracolumbar lesions in this series. Some pain is present to some degree in essentially all patients with metastatic spinal involvement, and, can be so severe that basic activities such as walking are difficult. ${ }^{15}$ Pain associated with spinal metastases is typically constant, localized, debilitating, and often worse at night. ${ }^{30}$ In addition to decreased functional mobility, this can result in sleep loss and severe depression. ${ }^{19}$ In this series, we demonstrated an $85 \%$ incidence of improved pain symptoms postsurgery. In another $15 \%$ of patients the pain was unchanged, and none reported worsening pain related to surgery. These findings are consistent with the generally high rate of pain relief reported after surgery for metastatic tumors in the literature. ${ }^{25}$ Weigel, et al., ${ }^{56}$ reported at least moderate pain relief in $89 \%$ of patients after performing anterior decompressive surgery and stabilization. Similarly, Rompe, et al., ${ }^{44}$ and Hussein, et al. ${ }^{27}$ documented pain relief in approximately $90 \%$ of cases. Shimizu, et al., ${ }^{48}$ and Cahill and $\mathrm{Ku}-$ mar $^{7}$ both reported $100 \%$ pain relief after posterior surgical approaches for metastatic spinal tumor decompression and stabilization, which seems very remarkable for spinal reconstruction for metastases in a rather diverse group of patients with varied symptomatology.

Spinal cord compression and/or instability from metastases can result from direct invasion by tumor, disease-related fracture, or osteoblastic bone reaction. ${ }^{25,27,32,43,53} \mathrm{De}$ pending on the mechanism of spinal cord compression or instability, there are a number of surgical approaches available to the spine surgeon. In general, laminectomy for decompression of spinal metastatic tumors has fallen out of favor because most spinal metastases originate in the vertebral body, and laminectomy is a potentially destabilizing procedure when there is anterior column support failure that results in progressive kyphotic deformity and neurological injury. ${ }^{25}$
TABLE 4

Number of vertebral levels treated in 58 patients

\begin{tabular}{cc}
\hline \hline No. of Levels & No. (\%) \\
\hline 1 & $36(62)$ \\
2 & $13(22)$ \\
3 & $8(14)$ \\
4 & $1(2)$ \\
total & $58(100)$ \\
\hline
\end{tabular}

The majority of patients in this series $(62 \%)$ underwent surgery for single-level disease, another $22 \%$ underwent two-level vertebrectomy, and in $14 \%$ three levels were reconstructed. Only one patient underwent a four-level vertebrectomy and reconstruction. In the series reported here, 39 patients $(52 \%)$ underwent anterior approaches only, whereas another 19 (48\%) underwent combined anteroposterior approaches. Similarly to other authors, ${ }^{17}$ we found the simultaneous anteroposterior approach to be both safe and effective, particularly for thoracic spine tumor resection. Although this series did not include any posterior or posterolateral tumor resections and reconstructions alone, we believe that selected cases of metastatic spinal involvement predominantly involving only the posterior spinal elements can be treated with laminectomy for decompression and stabilization if need be. Also, some selected patients with unacceptably high medical risks associated with the anterior surgical approach may benefit from a modified posterior or posterolateral transpedicular or costotransversectomy approach made using instrumented stabilization. Although these reports indicate results comparable to surgery via the anterior approach, ${ }^{1,12}$ complete ventral decompression and reconstruction comparable to that achievable with open anteroposterior procedures seems unlikely.

Several authors believe that the morbidity associated with anterior thoracolumbar approaches is not justified for the majority of patients with metastatic spinal disease..$^{35,44}$ Rompe, et al., reviewed their results in 50 patients who underwent posterior surgical decompression and fusion via a posterior approach with the use of long segmental hook instrumentation alone. Twenty-six patients experienced a preoperative neurological deficit, 14 (54\%) of which improved at least one Frankel grade postoperatively. ${ }^{18}$ One patient (4\%) was worse after surgery and 11 (42\%) remained unchanged. The authors concluded that posterior surgical decompression and fusion alone was appropriate in cases of multilevel metastatic disease that would be difficult to manage via an anterior approach. We agree that posterior instrumentation and fusion is appropriate for multilevel cases, but anterior or anteroposterior surgery is preferable for focal lesions requiring one-, two-, or three-level vertebrectomy. Interestingly, the only two cases of hardwarerelated failure in the report by Rompe, et al., ${ }^{44}$ occurred in patients with single-level disease, and we believe that these patients may do well with an anterior or anteroposterior procedure. Similarly, Shimizu, et al., ${ }^{48}$ reported similar rates of neurological improvement in a small study of 11 patients with multilevel metastatic disease, and nine patients $(82 \%)$ attained improved neurological function after posterior decompression and stabilization. 
TABLE 5

Ambulation status in 58 patients who underwent surgery for spinal metastases

\begin{tabular}{lccc}
\hline \hline \multicolumn{1}{c}{ Status } & $\begin{array}{r}\text { Total Patients } \\
\text { w/ Status (\%) }\end{array}$ & $\begin{array}{c}\text { Remained Ambulatory } \\
\text { Until Death (\%) }\end{array}$ & $\begin{array}{c}\text { Nonambulatory } \\
\text { at Death (\%) }\end{array}$ \\
\hline $\begin{array}{l}\text { ambulatory preop } \\
\text { nonambulatory preop }\end{array}$ & $24(100)$ & $32(94)$ & $2(6)^{*}$ \\
$9(100)$ & $15(62)$ & $9(38) \dagger$ \\
\hline
\end{tabular}

* After initially being ambulatory postoperatively until the last months of life.

$\dagger$ Never regained ambulation after reconstructive surgery.

An anterior approach to metastatic tumor surgery in the thoracolumbar spine has several distinct advantages. ${ }^{31}$ Anterior surgery provides the most direct route for decompression and tumor resection that also allows for effective reconstruction of the weight-bearing anterior vertebral column and short-segment fixation with potentially improved wound healing. ${ }^{21}$ Sundaresan, et al., ${ }^{51}$ reported on a prospective series of 54 patients who underwent surgery for metastatic spinal tumors, and $83 \%$ of these patients underwent anterior or anterolateral approaches. Forty-four percent of patients were nonambulatory before surgery because of a neurological deficit causing weakness, or pain preventing ambulation. Following surgery, 100\% were ambulatory and $90 \%$ of patients had improvement in the pain, with an overall complication rate of $20 \%$.

In our series, $16(57 \%)$ of the 28 patients with incomplete incontinence preoperatively had improvement in bladder function on clinical review postsurgery, whereas no patient with complete incontinence preoperatively had improvement in bladder function postoperatively, which is consistent with other results published in the literature..$^{56} \mathrm{Of}$ the 31 patients ambulating preoperatively, 29 (94\%) remained ambulatory postoperatively, whereas only two of these patients $(6 \%)$ became nonambulatory before they died of their underlying disease. Our experience with these patients and with the 21 patients who were nonambulatory preoperatively, $12(57 \%)$ of whom regained ambulation function, strongly supports the premise that quality of life can be dramatically improved, with long-term functional efficacy following major reconstructive surgery for spinal metastases.

Weigel, et al., ${ }^{56}$ reported the outcomes for a variety of approaches in a nonrandomized, retrospective review of 45 patients who underwent surgery for neurological deficits resulting from disease that had metastasized to the spine. In their study, $62 \%$ of patients improved after anterior surgery, whereas $50 \%$ improved after laminectomy. King, et al., ${ }^{29}$ reported a $50 \%$ incidence of neurological improvement of at least one Frankel grade in 20 patients following anterior decompression combined with posterior stabilization without laminectomy. Although these reports indicate that anterior surgical decompression and stabilization is more effective than laminectomy and posterior spinal instrumentation, it is difficult if not impossible to draw conclusions based on this type of data. Currently there are no randomized, prospective studies available.

Another indication for anterior thoracolumbar reconstructive surgery to treat metastatic disease is spinal instability. Harrington ${ }^{22}$ reported on 77 patients with spinal instability caused by metastatic disease-related fractures of one or more vertebrae. Surgery consisted of anterior decompression and stabilization with methyl methacrylate augmented by Knodt distraction rods positioned anteriorly. Of the 63 patients with major preoperative neurological impairment, 26 experienced complete neurological recovery, 16 improved significantly, 20 remained unchanged, and one patient deteriorated. Pain relief was achieved in 72 patients. Follow-up duration ranged from 31 to 146 months, and there was one reported wound infection among the 83 anterior stabilization procedures.

Due to recent advances in the medical management of certain types of tumors, such as breast, renal, and prostate carcinoma, longer survival times are being achieved compared with those published in the medical literature from earlier decades. ${ }^{25}$ Our protocol is that patients in whom expected survival is at least 6 months may be considered for palliative surgery to provide and maintain ambulatory status. Numerous factors are taken into consideration, including overall health, nutrition, biological behavior of the primary tumor, and extent of preoperative neurological deficit. ${ }^{46,49,55}$ At the time of this review, although only 14 patients $(24 \%)$ were still living, the mean survival duration was 13 months (range 3-38 months). Whether improved survival occurs because ambulation is maintained remains unproven, but it is feasible.

Tokuhashi, et al., ${ }^{55}$ discussed survival after surgery for spinal metastases in 64 patients who were similar to the patient population in our series. These authors generated a scoring system based on multiple parameters including general condition, number of spinal metastases, number of extraspinal bone metastases, presence of lesions in organs, location of the primary lesion, and the severity of spinal cord injury. Although no single parameter was predictive, they were able to predict survival of greater or less than 12 months or survival of greater or less than 3 months with high degrees of accuracy. Although we did not use the Tokuhashi scoring system, it appears that this could be a valuable tool that would aid in making preoperative decisions.

In particular there has been controversy over the Tokuhashi system using the patients' preoperative neurological

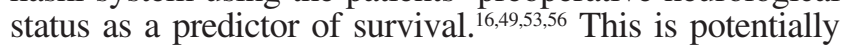
related to a rather simplistic grading system used by Tokuhashi in which spinal cord deficits are divided into motor complete (Frankel Grade A or B), motor incomplete (Frankel Grade C or D), or intact (Frankel Grade E).

The mean survival duration after spinal cord compression-induced paraplegia has been reported as approximately 3.4 months. ${ }^{56}$ Because 5 to $10 \%$ of patients with cancer will suffer from neurological injury, decompressive surgery is the most effective treatment for spinal cord compression. $2,4,7,15,42,44,56$ Radiation therapy is useful for radiationsensitive tumors (plasmacytomas) and typically does not result in rapid improvement when significant neurological deficits occur. It is therefore limited to lesions with minimal spinal cord compression. When used alone, radiation therapy does not result in a lasting improvement. As detailed in a series of 43 patients reported by Sundaresan, et al., ${ }^{52}$ neurological improvement occurred in $45 \%$ of those treated with radiation therapy alone, whereas surgery before or after radiotherapy resulted in improvement in 10 and $60 \%$, respectively. In the short term, radiation therapy may be more effective in patients with no evidence of bone compression. $^{39}$ 


\section{Posttreatment Complications}

Anterior approaches to the thoracic and lumbar spine have potentially serious complications. ${ }^{38}$ We had a $21 \%$ incidence of minor complications, there were no major complications (including death) associated with surgery, and there were no new neurological complications. In addition, we had to perform repeated surgery in 12 patients (mean 7.6 months postoperatively) in this series to provide further decompression following disease progression. We do not believe that this is necessarily a complication but rather that it represents the natural history of metastatic disease.

\section{Alternative and Future Therapies}

We generally recommend that patients receive radiation therapy at 6 weeks postoperatively to allow time for the skin as well as the construct to heal. During the 6-week followup period the patient also undergoes a new set of plain $\mathrm{x}$-ray studies to assess instrumentation and alignment as well as a CT scan or MR image to evaluate the extent of resection. Radiation therapy for metastatic spinal tumors in the absence of neurological deficit, intractable pain, or spinal instability is currently an acceptable treatment. In some inherently radioresistant tumors, however, such as renal cell and gastrointestinal lesions, less than $50 \%$ of tumors respond to this therapy. ${ }^{45,54}$ The potential side effects and complications of radiotherapy must be taken into consideration. ${ }^{34}$ Surgery is generally not performed until at least 3 weeks after external-beam radiotherapy is performed in the zone of treatment because of the harmful effects of this modality on wound healing. ${ }^{25}$ Spinal instability is obviously not treated by radiotherapy, and in some cases this treatment can cause further bone weakening and instability, as occurred in the patients in this series who had plasmacytomas. . $^{3,10,13,25}$

Vertebroplasty has recently been introduced as a method of treatment for metastatic disease-related spinal fractures. ${ }^{3,10,13}$ This technique can be especially useful in patients with limited anticipated survival, in poor surgical candidates, in patients who have received maximum radiation doses, and in those with significant vertebral body collapse and axial pain. ${ }^{3,13,40}$ Vertebroplasty can also be performed as a complement to radiotherapy to provide immediate pain relief and stabilization. ${ }^{40}$ Patients who may benefit most from this technique have severe, localized, mechanical back pain related to vertebral collapse. Nevertheless, vertebroplasty is contraindicated in patients with spinal instability or with spinal cord compression due to epidural tumor extension and who require surgical intervention. ${ }^{11,13}$

\section{CONCLUSIONS}

Reconstructive thoracolumbar vertebrectomy has been established as an effective treatment option in patients with metastatic disease. Patients typically present with progressive neurological deficit and severe pain that threatens their neurological function and quality of life. Patients are encouraged to receive maximal medical therapy (radiation or chemotherapy) before surgery to reduce the tumor burden, and often postoperatively as well. Anterior decompression and stabilization of the spine in these patients allows direct access to the pathological entity for en bloc resection of the tumors and decompression of the spinal cord. Significant neurological improvement and decreased pain can be obtained in select patients. More importantly, we have found that quality of life is a major factor that can be significantly improved with surgery, primarily by maintaining the patient's ambulatory status and bladder function.

\section{References}

1. Akeyson EW, McCutcheon IE: Single-stage posterior vertebrectomy and replacement combined with posterior instrumentation for spinal metastasis. J Neurosurg 85:211-220, 1996

2. Bansal S, Brady LW, Olsen A, et al: The treatment of metastatic spinal cord tumors. JAMA 202:686-688, 1967

3. Barr JD, Barr MS, Lemley TJ, et al: Percutaneous vertebroplasty for pain relief and spinal stabilization. Spine 25:923-928, 2000

4. Barron KD, Hirano A, Araki S, et al: Experiences with metastatic neoplasms involving the spinal cord. Neurology 9:91-106, 1959

5. Black P: Spinal metastasis: current status and recommended guidelines for management. Neurosurgery 5:726-746, 1979

6. Brihaye J, Ectors P, Lemort M, et al: The management of spinal epidural metastases. Adv Tech Stand Neurosurg 16:121-176, 1988

7. Cahill DW, Kumar R: Palliative subtotal vertebrectomy with anterior and posterior reconstruction via a single posterior approach. J Neurosurg 90 (Suppl 1):42-47, 1999

8. Comey CH, McLaughlin MR, Moossy J: Anterior thoracic corpectomy without sternotomy: a strategy for malignant disease of the upper thoracic spine. Acta Neurochir (Wien) 139:712-718, 1997

9. Cooper PR, Errico TJ, Martin R, et al: A systematic approach to spinal reconstruction after anterior decompression for neoplastic disease of the thoracic and lumbar spine. Neurosurgery 32: $1-8,1993$

10. Cortet B, Cotten A, Boutry N, et al: Percutaneous vertebroplasty in patients with osteolytic metastases or multiple myeloma. Rev Rhum Engl Ed 64:177-183, 1997

11. Cotten A, Dewatre F, Cortet B, et al: Percutaneous vertebroplasty for osteolytic metastases and myeloma: effects of the percentage of lesion filling and the leakage of methyl methacrylate at clinical follow-up. Radiology 200:525-530, 1996

12. Cybulski GR, Stone JL, Opesanmi O: Spinal cord decompression via a modified costotransversectomy approach combined with posterior instrumentation for management of metastatic neoplasms of the thoracic spine. Surg Neurol 35:280-285, 1991

13. Deramond H, Depriester C, Galibert P, et al: Percutaneous vertebroplasty with polymethylmethacrylate. Technique, indications, and results. Radiol Clin North Am 36:533-546, 1998

14. DeWald RL, Bridwell KH, Prodromas C, et al: Reconstructive spinal surgery as palliation for metastatic malignancies of the spine. Spine 10:21-26, 1985

15. Durr HR, Maier M, Pfahler M, et al: Surgical treatment of osseous metastases in patients with renal cell carcinoma. Clin Orthop Relat Res 367:283-290, 1999

16. Enkaoua EA, Doursounian L, Chatellier G, et al: Vertebral metastases: a critical appreciation of the preoperative prognostic tokuhashi score in a series of 71 cases. Spine 22:2293-2298, 1997

17. Fourney DR, Abi-Said D, Rhines LD, et al: Simultaneous anterior-posterior approach to the thoracic and lumbar spine for the radical resection of tumors followed by reconstruction and stabilization. J Neurosurg 94 (Suppl 2):232-244, 2001

18. Frankel HL, Hancock DO, Hyslop G, et al: The value of postural reduction in the initial management of closed injuries of the spine with paraplegia and tetraplegia. I. Paraplegia 7: 179-192, 1969

19. Garfin SR, Yuan HA, Reiley MA: New technologies in spine: 
kyphoplasty and vertebroplasty for the treatment of painful osteoporotic compression fractures. Spine 26:1511-1515, 2001

20. Gilbert RW, Kim JH, Posner JB: Epidural spinal cord compression from metastatic tumor: diagnosis and treatment. Ann Neurol 3:40-51, 1978

21. Gokaslan ZL, York JE, Walsh GL, et al: Transthoracic vertebrectomy for metastatic spinal tumors. J Neurosurg 89:599-609, 1998

22. Harrington KD: Anterior decompression and stabilization of the spine as a treatment for vertebral collapse and spinal cord compression from metastatic malignancy. Clin Orthop Relat Res 233:177-197, 1988

23. Harrington KD: Metastatic disease of the spine. J Bone Joint Surg Am 68:1110-1115, 1986

24. Harrington KD: Orthopedic surgical management of skeletal complications of malignancy. Cancer 80 (Suppl 8): 1614-1627, 1997

25. Heary RF, Bono CM: Metastatic spinal tumors. Neurosurg Focus 11(6): $\mathrm{E} 1,2001$

26. Hirschfeld A, Beutler W, Seigle J, et al: Spinal epidural compression secondary to osteoblastic metastatic vertebral expansion. Neurosurgery 23:662-665, 1988

27. Hussein AA, El-Karef E, Hafez M: Reconstructive surgery in spinal tumors. Eur J Surg Oncol 27:196-199, 2001

28. Johnson JP, Pare LS, Torres RA: Thoracolumbar body replacement: material and techniques. Contemp Neurosurg 20:1-9, 1998

29. King GJ, Kostuik JP, McBroom RJ, et al: Surgical management of metastatic renal carcinoma of the spine. Spine 16:265-271, 1991

30. Kostuik JP: Differential diagnosis and surgical treatment of metastatic spine tumors, in Frymoyer JW (ed): The Adult Spine, ed 2. Philadelphia: Lippincott-Raven, 1997, pp 989-1014

31. Kurz LT, Pursel SE, Herkowitz HN. Modified anterior approach to the cervicothoracic junction. Spine 16 (Suppl 10): S542-S547, 1991

32. Loblaw DA, Laperrier NJ: Emergency treatment of malignant extradural spinal cord compression: an evidence-based guideline. J Clin Oncol 16:1613-1624, 1998

33. Malawer MM, Delaney TF: Treatment of metastatic cancer to bone, in Devita VT, Hellman S, Rosenberg SA (eds): Cancer. Principles and Practice of Oncology, ed 4. Philadelphia: Lippincott-Raven, 1993, p 2225

34. Medin PM, Solberg TD, De Salles AA, et al: Investigations of a minimally invasive method for treatment of spinal malignancies with LINAC stereotactic radiation therapy: accuracy and animal studies. Int J Radiat Oncol Biol Phys 52:1111-1122, 2002

35. Moore AJ, Uttley D: Anterior decompression and stabilization of the spine in malignant disease. Neurosurgery 24:713-717, 1989

36. Nagashima C, Iwasaki T, Okada K, et al: Reconstruction of the atlas and axis with wire and acrylic after metastatic destruction. Case report. J Neurosurg 50:668-673, 1979

37. Olerud C, Jonsson B: Surgical palliation of symptomatic spinal metastases. Acta Orthop Scand 67:513-522, 1996

38. Oskouian RJ Jr, Johnson JP. Vascular complications in anterior thoracolumbar spinal reconstruction. J Neurosurg (Suppl 1) 96: $1-5,2002$
39. Pigott KH, Baddeley H, Maher EJ: Pattern of disease in spinal cord compression on MRI scan and implications for treatment. Clin Oncol 6:7-10, 1994

40. Pilitsis JG, Rengachary SS: The role of vertebroplasty in metastatic spinal disease. Neurosurg Focus 11(6):E9, 2001

41. Posner JB: Back pain and epidural spinal cord compression. Med Clin North Am 71:185-205, 1987

42. Posner JB: Neurological complications of systemic cancer. Med Clin North Am 55:625-646, 1971

43. Rodriguez M, Dinapoli RP: Spinal cord compression: with special reference to metastatic epidural tumors. Mayo Clin Proc 55:442-448, 1980

44. Rompe JD, Eysel P, Hopf C, et al: Decompression/stabilization of the metastatic spine. Cotrel-Dubousset-Instrumentation in 50 patients. Acta Orthop Scand 64:3-8, 1993

45. Ryu SI, Chang SD, Kim DH, et al: Image-guided hypo-fractionated stereotactic radiosurgery to spinal lesions. Neurosurgery 49:838-846, 2001

46. Saengnipanthkul S, Jirarattanaphochai K, Rojviroj S, et al: Metastatic adenocarcinoma of the spine. Spine 17:427-430, 1992

47. Shimizu K, Shikata J, Iida H, et al: Posterior decompression and stabilization for multiple metastatic tumors of the spine. Spine 17:1400-1404, 1992

48. Siegal T: Surgical decompression of anterior and posterior malignant epidural tumors compressing the spinal cord: a prospective study. Neurosurgery 17:424-432, 1985

49. Sioutos PJ, Arbit E, Meshulam CF, et al: Spinal metastases from solid tumors. Analysis of factors affecting survival. Cancer 76:1453-1459, 1995

50. Steinmetz MP, Mekhail A, Benzel EC: Management of metastatic tumors of the spine: strategies and operative indications. Neurosurg Focus 11(6):E2, 2001

51. Sundaresan N, Digiacinto GV, Hughes JE, et al: Treatment of neoplastic spinal cord compression: results of a prospective study. Neurosurgery 29:645-650, 1991

52. Sundaresan N, Scher H, DiGiacinto GV, et al: Surgical treatment of spinal cord compression in kidney cancer. J Clin Oncol 4:1851-1856, 1986

53. Sundaresan N, Shah J, Foley KM, et al: An anterior surgical approach to the upper thoracic vertebrae. J Neurosurg 61: 686-690, 1984

54. Takacs I, Hamilton AJ: Extracranial stereotactic radiosurgery: applications for the spine and beyond. Neurosurg Clin N Am 10:257-270, 1999

55. Tokuhashi Y, Matsuzaki H, Toriyama S, et al: Scoring system for the preoperative evaluation of metastatic spine tumor prognosis. Spine 15:1110-1113, 1990

56. Weigel B, Maghsudi M, Neumann C, et al: Surgical management of symptomatic spinal metastases. Postoperative outcome and quality of life. Spine 24:2240-2246, 1999

Manuscript received May 31, 2005.

Accepted in final form July 8, 2005

Address reprint requests to: J. Patrick Johnson, M.D., 444 South San Vicente Boulevard, Suite 800, Los Angeles, California 90048. email: johnsonjp@cshs.org. 